\title{
A Systematic Review of Family-Based Interventions Targeting Alcohol Misuse and Their Potential to Reduce Alcohol-Related Harm in Indigenous Communities
}

\author{
BIANCA CALABRIA, B.PSYCH. (HONS.), ${ }^{a, *}$ ANTON CLIFFORD, PH.D., ${ }^{b}$ ANTHONY P. SHAKESHAFT, PH.D., ${ }^{a}$ AND \\ CHRISTOPHER M. DORAN, PH.D. ${ }^{c, d, e}$ \\ ${ }^{a}$ National Drug and Alcohol Research Centre, University of New South Wales, Sydney, Australia \\ ${ }^{b}$ Queensland Alcohol and Drug Research and Education Centre, School of Population Health, University of Queensland, Brisbane, \\ Australia \\ ${ }^{c}$ Hunter Medical Research Centre, Newcastle, Australia \\ ${ }^{d}$ University of Newcastle, Newcastle, Australia \\ ${ }^{e} H u n t e r$ Valley Research Foundation, Newcastle, Australia
}

\begin{abstract}
Objective: Alcohol misuse is a major risk factor for harm in indigenous communities. The indigenous family unit is often the setting for, and is most adversely affected by, alcohol-related harm. Therefore, family-based alcohol interventions offer great potential to reduce alcohol-related harm in indigenous communities. This systematic review aims to identify peer-reviewed published evaluations of familybased alcohol interventions, critique the methodological quality of those studies, describe their intervention characteristics, and identify which interventions appear most promising to reduce alcohol-related harm in indigenous communities. Method: Eleven electronic databases were searched. The reference lists of reviews of family-based approaches focused on alcohol interventions were hand-searched for additional relevant studies not identified by the electronic database search. Results: Initially, 1,369 studies were identified, of which $21 \%(n=142)$ were
\end{abstract}

classified as intervention studies. Nineteen intervention studies were family-based alcohol interventions. Eleven of these studies included family members in the treatment of problem drinkers, and eight studies specifically targeted family members of problem drinkers. Methodological quality of studies varied, particularly in relation to study design, including confounding variables in the analyses, and follow-up rates. Conclusions: The evidence for the effectiveness of family-based alcohol interventions is less than optimal, although the reviewed studies did show improved outcomes. Given the important role of family in indigenous communities, there is merit in exploring family-based approaches to reduce alcohol-related harms. Tailored family-based approaches should be developed that include direct consultation with targeted indigenous communities. (J. Stud. Alcohol Drugs, 73, 477-488, 2012)
$I_{n}^{\mathrm{N}}$ NDIGENOUS PEOPLES HAVE A HISTORICAL continuity with pre-colonial traditional societies. They derive a sense of identify from, and have a strong connection to, their traditional lands. Indigenous peoples communicate their strong understanding of and connection with their past through varied and distinct lifestyle and cultural practices. Adaptations away from traditional land, lifestyle, and culture do not negate indigenous identity (Coates, 2004).

In countries where alcohol use is culturally acceptable, a greater proportion of indigenous people abstain from alcohol use compared with the general population; however, among those who do drink, indigenous people consume alcohol at riskier levels (Australian Department of Human Services and Health, 1995; Bramley et al., 2003; First Nations/First Nationals Information Governance Committee, 2007). In countries in which alcohol is consumed by only a minority of the population, indigenous people are more likely to consume

Received: August 30, 2011. Revision: November 13, 2011.

This research was supported by National Health and Medical Research Council of Australia Grant 630643.

* Correspondence may be sent to Bianca Calabria at the National Drug and Alcohol Research Centre, Building R3, 22-32 King Street, Randwick, NSW 2031, Australia, or via email at: b.calabria@unsw.edu.au. alcohol than those in the general population (Subramanian et al., 2006). As a result, indigenous people experience a disproportionately high burden of alcohol-related harm compared with the general population (Calabria et al., 2010; Centers for Disease Control and Prevention [CDC], 2008). Alcoholrelated mortality rates are between two (CDC, 2008; Connor et al., 2004) and eight (Begg et al., 2007; Vos et al., 2003) times higher among indigenous populations compared with the general population. The main contributors to alcohol-related mortality among indigenous people are homicide and violence, injury, suicide (including self-inflicted injury), and road traffic accidents (Begg et al., 2007; Calabria et al., 2010; CDC, 2008; Connor et al., 2004; Vos et al., 2003). Despite these extraordinarily high rates of alcohol-related harm, indigenous peoples' access to health services and programs to reduce these harms is disproportionately low (Berry and Crowe, 2009; KnowledgeAssets, 2010). Mainstream services and programs are generally unacceptable and/or inappropriate for indigenous peoples (Dodgson and Struthers, 2005; Hayman et al., 2009), and indigenous-specific alcohol services are often lacking and/or inadequately resourced (Allison et al., 2004; Gray et al., 2010). As a consequence, indigenous peoples require improved access to acceptable and appropriate alcohol intervention services and programs. 
The harms resulting from alcohol misuse extend beyond drinkers to their families and communities. Family members and friends who have regular contact with a problem drinker are at increased risk of alcohol-related violence, conflict, sexual assault, psychological abuse, and/or neglect (Kelly and Kowalyszyn, 2003; Laslett et al., 2010; Seale et al., 2002). These negative personal relationships can result in psychological distress (Laslett et al., 2010; Seale et al., 2002). Conversely, positive family relationships are the foundation for community cohesion among indigenous groups (McLennan and Khavarpour, 2004) and can promote behavioral change (Nagel and Thompson, 2010). Given the increased risk of alcohol-related harm among relatives of problem drinkers and the central role that family relationships play in indigenous communities, family member participation in interventions to help problem drinkers reduce their alcohol consumption is likely to result in better outcomes than interventions that target problem drinkers only.

Family-based interventions have proven to be effective in non-indigenous populations (Miller and Wilbourne, 2002; Smit et al., 2008; Templeton et al., 2010). Cultural adaptation of evidence-based interventions to increase their likelihood of proving acceptable and effective for indigenous people is, however, necessary and appropriate because of differences in their cultural values, knowledge bases, and levels of exposure to risk factors (Bernal et al., 2009; Lau, 2006). Despite calls for increased family support services for indigenous communities (Gray et al., 2010; Seale et al., 2006), the effectiveness and appropriateness of family-based interventions for reducing alcohol-related harm in indigenous communities is yet to be rigorously examined.

The aims of this study were threefold: first, to identify peer-reviewed publications of evaluations of family-based alcohol interventions; second, to critique the methodological quality of those studies and describe their intervention characteristics; and third, to identify which interventions appear most promising to reduce alcohol-related harm in indigenous communities.

\section{Method}

Sample

The search was limited to publications dated 2003-2010 (inclusive) to complement, rather than replicate, a previous review of family-based interventions, published in 2005 (Copello et al., 2005).

\section{Search strategy}

Figure 1 summarizes the databases searched, the search terms used, the exclusion criteria, and classification of included studies.
Consistent with methods detailed in the Cochrane Collaboration's Handbook: Systematic Reviews of Health Promotion and Public Health Interventions (Jackson, 2007) and with previous reviews (Calabria et al., 2011; Havard et al., 2008; Shakeshaft et al., 1997; Webb et al., 2009; Wood et al., 2006), the search strategy comprised two steps. First, consultation with a qualified archivist identified nine relevant electronic databases to search: Project Cork, EMBASE, ERIC, Family Studies Abstract, MEDLINE, Proquest Social Science Journals, PsycINFO, Sociological Abstracts, and Web of Science. Electronic databases were searched individually with specific search strings because this method is more effective at identifying relevant articles than a simultaneous search using generic search terms (Jackson, 2007). The search terms (modeled from a previous review; Calabria et al., 2011) "alcohol," "family," and "intervention" were integrated into database-specific search strings. The combined searches of the nine databases located 3,032 references that were imported into Endnote. An Endnote search for "intervention" was conducted to identify a manageable number of citations for review. The Endnote search identified 1,250 articles for classification. To maximize coverage of indigenous-specific studies, the Indigenous Australian Alcohol and Other Drugs Bibliographic Database (National Drug Research Institute) and the Indigenous HealthInfoNet (Australian Government Department of Health and Ageing) were searched using the same search terms. A total of 112 studies were identified for classification. These were reviewed using hardcopy printouts because the databases lack the capacity to export references to Endnote.

Second, reference lists from reviews of family-based approaches targeting alcohol $(n=44)$, identified by Step 1 , were hand-searched for relevant studies not yet identified. This process identified seven relevant studies (Doyle et al., 2003; Dutcher et al., 2009; Fals-Stewart et al., 2005; Howells and Orford, 2006; Latimer et al., 2003; Rychtarik and McGillicuddy, 2005; and Walitzer and Dermen, 2004).

\section{Classification of studies}

The abstracts of the 1,369 identified references were classified in a three-step process.

Step 1: Identification of studies for exclusion. Articles were excluded if (a) they did not focus on alcohol or the outcome or predictor variables did not include alcohol ( $n$ =249); (b) the subject of the research was not defined as a family member (e.g., parent, spouse, sibling, or child) or the outcome or predictor variables did not include family (e.g., family functioning or heritability) $(n=230)$; (c) they were not peer reviewed $(n=176)$; (d) they were not conducted in 2003-2010 $(n=10)$; or (e) they were animal studies $(n=3)$. Step 1 excluded 668 articles.

Step 2: Classification of studies. The remaining studies ( $n$ $=701$ ) were classified as either intervention studies or one of 
Database search: EMBASE, ERIC, Family studies abstracts, Indigenous Australian Alcohol and Other Drugs Bibliographic Database, Indigenous HealthInfoNet, Medline, Project Cork, Proquest Social Science Journals, PsycINFO, Sociological Abstracts, and Web of Science.

Separate search for each database using database specific search strings:

- Keywords used: alcohol, intervention/family intervention, family

- Limited (when possible) to: 2003-2010, peer-reviewed/scholarly articles, human subject, English language

Total of $\mathbf{1 , 3 6 2}$ citations/abstracts identified by the electronic database search (after deletion of duplicates).

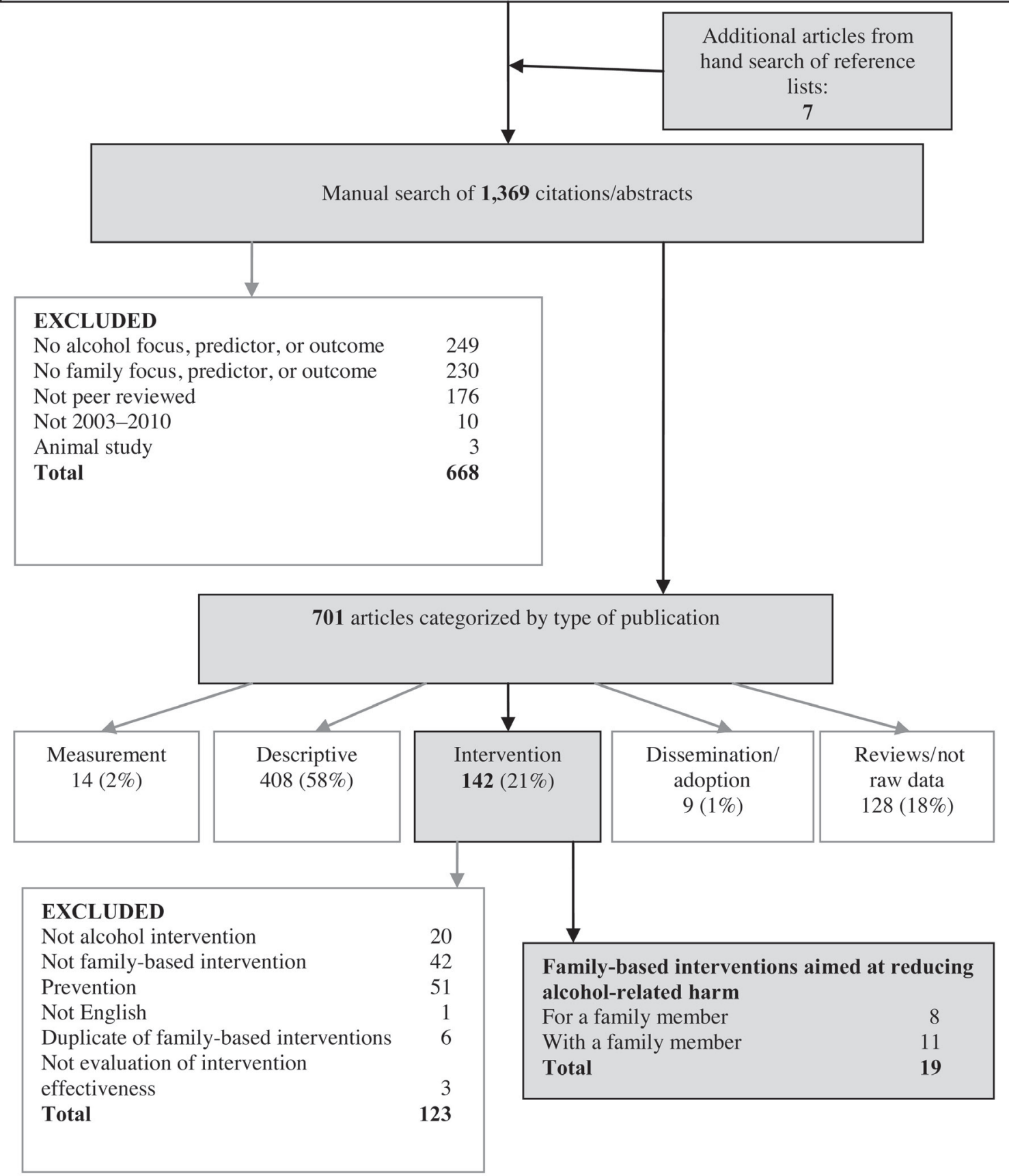

FIGURE 1. Flowchart indicating search strategy and classification of articles 
four other criteria derived and adapted from previous similar reviews (Calabria et al., 2011; Havard et al., 2008; Webb et al., 2009; Wood et al., 2006): (a) interventions, defined as evaluations or trials of family-based intervention approaches designed to reduce alcohol-related harm, or evaluations or trials of intervention approaches that included alcohol or family as an outcome or predictor variable $(n=142)$; (b) measurement, defined as articles concerned primarily with developing measurement instruments and/or testing the psychometric properties of measurement instruments $(n=14)$; (c) descriptive, defined as data-based descriptive, analytical research on alcohol-related harm and families $(n=408)$; (d) dissemination/adoption and acceptability/feasibility, defined as studies evaluating approaches for improving the uptake and delivery of alcohol interventions by health care practitioners, and/or the acceptability and/or feasibility of alcohol intervention delivery $(n=9)$; and (e) reviews, defined as literature reviews, non-data-based articles, and comments ( $n$ $=128)$. Step 2 excluded 559 articles. Ten percent $(n=71)$ of classified articles were reclassified by a blinded coauthor (A.C.) to crosscheck classifications performed by the first author (B.C.). The articles excluded in Step 1 were not crosschecked because they were not relevant for the review. Agreement between co-authors was approaching substantial $(\kappa=.58)$. Discrepancies were discussed and resolved. Sufficient agreement between co-authors deemed crosschecking more than $10 \%$ of article classifications unnecessary.

Step 3: Identification of family-based alcohol intervention studies. Of the 142 intervention articles identified, 123 were excluded for the following reasons: (a) they were not an alcohol intervention $(n=20)$, (b) they were not a familybased alcohol intervention $(n=42)$, (c) they were preventive interventions $(n=51)$, (d) they were not published in English $(n=1)$, (e) they were duplicate articles based on intervention studies already included $(n=6)$, or (f) they did not report on the effectiveness of an intervention (e.g., compared outcomes of ethnic groups participating in the intervention) $(n=3)$. Step 3 excluded 123 articles and identified 19 family-based intervention studies for critical review.

\section{Data extraction from studies}

Criteria for data extraction from studies were adapted from the Cochrane Collaboration's Handbook: Systematic Reviews of Health Promotion and Public Health Interventions (Jackson, 2007). The criteria relate to the intervention/s sample (including eligibility, size, age range, and percent male), outcomes measured, and cost calculations performed.

\section{Methodological critique of intervention studies}

Methodological quality was assessed using the Dictionary for the Effective Public Health Practice Project Quality Assessment Tool for Quantitative Studies (Jackson, 2007).
Sections $\mathrm{A}$ to $\mathrm{F}$ ( $\mathrm{A}=$ selection bias; $\mathrm{B}=$ allocation bias; $\mathrm{C}$ = confounders; $\mathrm{D}=$ blinding; $\mathrm{E}=$ data collection methods; and $\mathrm{F}=$ withdrawal and drop-outs) were coded weak, moderate, or strong, consistent with the component rating scale of the dictionary (Jackson, 2007). For Sections G (analysis) and $\mathrm{H}$ (intervention integrity), descriptive information was recorded, using dictionary recommendations as a guide.

\section{Results}

\section{Intervention type and setting}

All family-based interventions identified were counselingbased interventions: 11 targeted problem drinkers and their family members, and 8 targeted family members of problem drinkers only (Table 1). The delivery mode for interventions targeting problem drinkers and their family members included individual sessions (Boyd-Ball, 2003; Liddle et al., 2009; Nattala et al., 2010; O'Farrell et al., 2008; Slesnick and Prestopnik, 2009; Vedel et al., 2008), individual sessions with concurrent group and/or family/couples sessions (Doyle et al., 2003; Esposito-Smythers et al., 2006; Fals-Stewart et al., 2005; Slesnick and Prestopnik, 2009), group sessions with concurrent family/couples sessions (Doyle et al., 2003; Latimer et al., 2003), family/couples sessions (Fals-Stewart et al., 2005; Nattala et al., 2010; Slesnick and Prestopnik, 2009; Vedel et al., 2008), or group sessions (Fals-Stewart et al., 2005; Latimer et al., 2003; Liddle et al., 2009; Walitzer and Dermen, 2004). Interventions targeting problem drinkers and their family members were delivered in tertiary health care settings (Boyd-Ball, 2003; Doyle et al., 2003; EspositoSmythers et al., 2006; Fals-Stewart et al., 2005; Latimer et al., 2003; Liddle et al., 2009; Nattala et al., 2010; O'Farrell et al., 2008; Vedel et al., 2008); a research center (Walitzer and Dermen, 2004); and within a home, an office, or a runaway shelter (Slesnick and Prestopnik, 2009). The delivery mode for interventions targeting family members of problem drinkers included individual sessions (Copello et al., 2009; Dutcher et al., 2009; Hansson et al., 2004, 2006; Howells and Orford, 2006; Landau et al., 2004), group sessions (de los Angeles Cruz-Almanza et al., 2006; Hansson et al., 2004; Rychtarik and McGillicuddy, 2005), or a combination of both (Rychtarik and McGillicuddy, 2005). Interventions targeting family members of problem drinkers were delivered in primary health care settings (Copello et al., 2009; de los Angeles Cruz-Almanza et al., 2006), tertiary health care settings (Dutcher et al., 2009; Howells and Orford, 2006; Landau et al., 2004), and a university (Hansson et al., 2006).

\section{Sample population targeted by interventions}

One intervention specifically targeted an indigenous population: Native Americans (Boyd-Ball, 2003). Across 
CALABRIA ET AL.

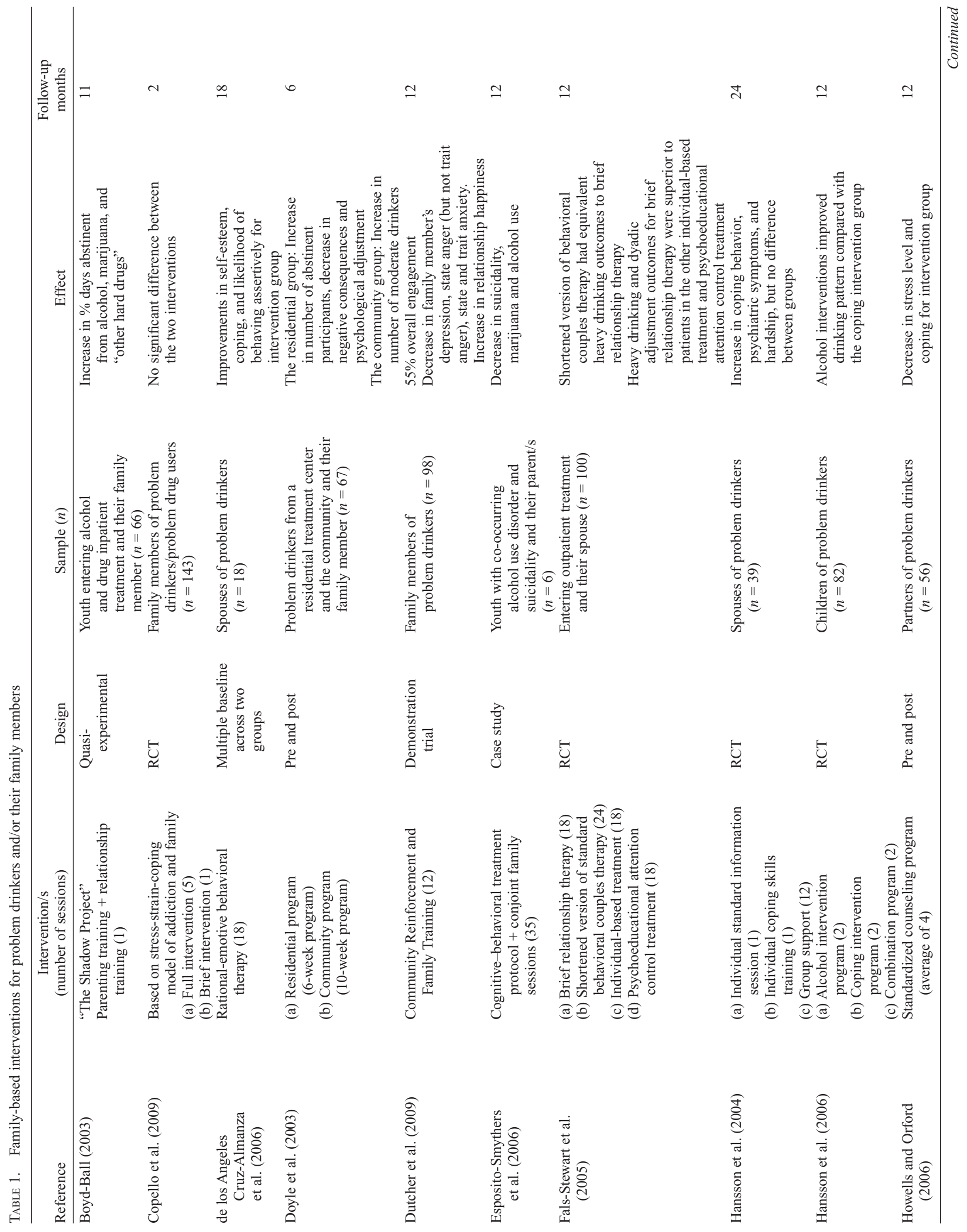




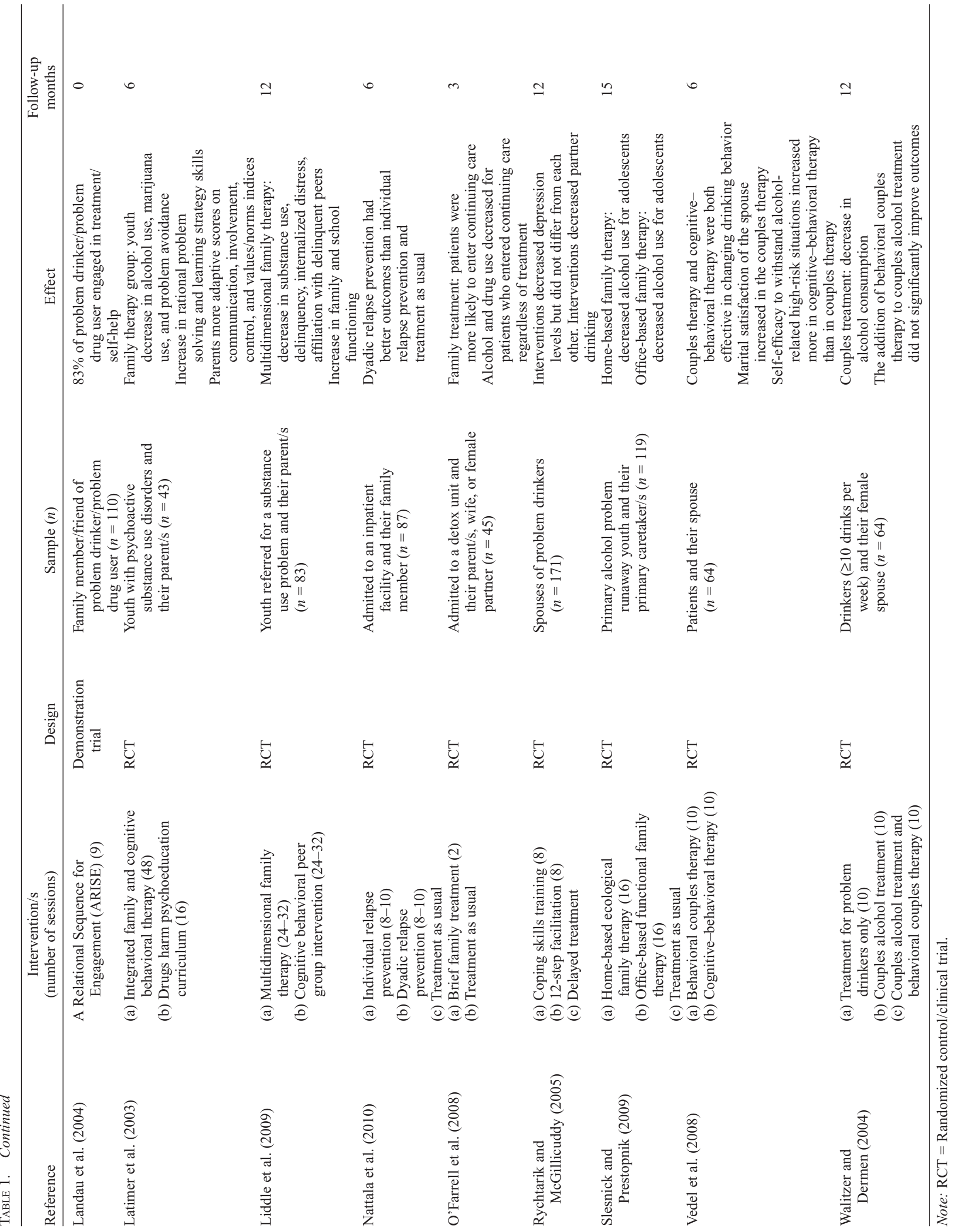


interventions for problem drinkers and their family members, problem drinking youth (Boyd-Ball, 2003; Esposito-Smythers et al., 2006; Latimer et al., 2003; Liddle et al., 2009; Slesnick and Prestopnik, 2009) or adults (Doyle et al., 2003; FalsStewart et al., 2005; Nattala et al., 2010; O'Farrell et al., 2008; Vedel et al., 2008; Walitzer and Dermen, 2004) were targeted. Types of family members targeted in the treatment of problem drinkers included parents (Esposito-Smythers et al., 2006; Latimer et al., 2003; Liddle et al., 2009) or other family members (Boyd-Ball, 2003; Slesnick and Prestopnik, 2009) for adolescent problem drinkers, and spouse (FalsStewart et al., 2005; Vedel et al., 2008; Walitzer and Dermen, 2004) or other family members (Doyle et al., 2003; Nattala et al., 2010; O'Farrell et al., 2008) for adult problem drinkers. Interventions for family members only targeted a spouse (de los Angeles Cruz-Almanza et al., 2006; Hansson et al., 2004; Howells and Orford, 2006; Rychtarik and McGillicuddy, 2005) or other family members (Copello et al., 2009; Dutcher et al., 2009; Hansson et al., 2006; Landau et al., 2004) of a problem drinker. Samples ranged in age from 12 to 78 years. The percentage range of male participants was $17 \%$ (Esposito-Smythers et al., 2006) to 100\% (Fals-Stewart et al., 2005; Nattala et al., 2010; Walitzer and Dermen, 2004) for interventions targeting problem drinkers and $0 \%$ (de los Angeles Cruz-Almanza et al., 2006) to 31\% (Landau et al., 2004) for interventions targeting family members.

\section{Eligibility criteria}

Alcohol use/dependence eligibility criteria for problem drinkers whose family members were involved in their treatment varied across studies and were treatment samples (Boyd-Ball, 2003; Doyle et al., 2003; Liddle et al., 2009), alcohol dependence/abuse diagnosis (Esposito-Smythers et al., 2006; Fals-Stewart et al., 2005; Latimer et al., 2003; Nattala et al., 2010; O'Farrell et al., 2008; Vedel et al., 2008), or problem alcohol use (Slesnick and Prestopnik, 2009; Walitzer and Dermen, 2004).

Eligibility criteria for family members of problem drinkers were the family member's perception that their relative had a drinking problem defined by the family member's reports of problematic patterns of alcohol consumption (Dutcher et al., 2009; Hansson et al., 2004, 2006; Howells and Orford, 2006; Landau et al., 2004; Rychtarik and McGillicuddy, 2005) or the family member's perceptions of the impact of the problem drinker's negative behavior on their well-being (Copello et al., 2009; de los Angeles CruzAlmanza et al., 2006).

\section{Data collection methods}

Self-report and non-self-report measures. All 19 studies used self-report measures. Eight studies conducted interviews (Doyle et al., 2003; Fals-Stewart et al., 2005; Hansson et al., 2004, 2006; Latimer et al., 2003; Rychtarik and McGillicuddy, 2005; Vedel et al., 2008; Walitzer and Dermen, 2004), and five used corroborated reports (Fals-Stewart et al., 2005; Latimer et al., 2003; Nattala et al., 2010; Rychtarik and McGillicuddy, 2005; Walitzer and Dermen, 2004). In six studies, non-self-report measures were also used: Two used urine tests (Latimer et al., 2003; Slesnick and Prestopnik, 2009), two used observational methods (Boyd-Ball, 2003; Liddle et al., 2009), and two checked medical records (Landau et al., 2004; O'Farrell et al., 2008).

Measurement instruments for alcohol use and/or dependence. Ten of the 11 studies targeting problem drinkers and their family members measured alcohol use and/or dependence with a validated instrument. Instruments were Timeline Followback interview (Doyle et al., 2003; EspositoSmythers et al., 2006; Fals-Stewart et al., 2005; Liddle et al., 2009; O'Farrell et al., 2008), the Alcohol Dependence Scale (Doyle et al., 2003; Walitzer and Dermen, 2004), Structured Clinical Interview for DSM-IV (Fals-Stewart et al., 2005; Vedel et al., 2008), Diagnostic Interview of Children and Adolescents (Latimer et al., 2003), the Adolescent Diagnostic Interview-Revised (Latimer et al., 2003), the Personal Experience Inventory (Latimer et al., 2003), the Problem Oriented Screening Instrument for Teenagers (Liddle et al., 2009), Form 90 (Nattala et al., 2010; Slesnick and Prestopnik, 2009), and the Alcohol Use Disorders Identification Test (AUDIT; Vedel et al., 2008). Two studies also used quantity and frequency questions (Vedel et al., 2008; Walitzer and Dermen, 2004).

Two of the eight studies targeting only family members of problem drinkers measured their alcohol consumption using the following validated instruments: the AUDIT (Hansson et al., 2004, 2006) and the Estimated Blood Alcohol Concentration Method (Hansson et al., 2006).

Outcome measures. The most frequently measured outcome for problem drinkers was alcohol consumption (BoydBall, 2003; Doyle et al., 2003; Esposito-Smythers et al., 2006; Fals-Stewart et al., 2005; Latimer et al., 2003; Liddle et al., 2009; Nattala et al., 2010; O'Farrell et al., 2008; Slesnick and Prestopnik, 2009; Vedel et al., 2008; Walitzer and Dermen, 2004), followed by illicit drug use (Boyd-Ball, 2003; Esposito-Smythers et al., 2006; Fals-Stewart et al., 2005; Latimer et al., 2003; Liddle et al., 2009; O'Farrell et al., 2008; Slesnick and Prestopnik, 2009). Primary outcomes recurrently measured for family members of problems drinkers were coping (Copello et al., 2009; de los Angeles CruzAlmanza et al., 2006; Hansson et al., 2004, 2006; Howells and Orford, 2006), self-esteem (Copello et al., 2009; de los Angeles Cruz-Almanza et al., 2006; Howells and Orford, 2006), and engagement in treatment service and/or help seeking (Dutcher et al., 2009; Howells and Orford, 2006; Landau et al., 2004; Rychtarik and McGillicuddy, 2005).

Family/marital functioning/satisfaction/cohesion was measured by eight studies (Doyle et al., 2003; Latimer et al., 
TABLE 2. Methodological adequacy

\begin{tabular}{|c|c|c|c|c|c|c|}
\hline Reference & $\begin{array}{l}\text { Selection } \\
\text { bias }(\mathrm{A})\end{array}$ & $\begin{array}{l}\text { Allocation } \\
\text { bias (B) }\end{array}$ & $\begin{array}{l}\text { Confounders } \\
\text { (C) }\end{array}$ & $\begin{array}{l}\text { Blinding } \\
\text { (D) }\end{array}$ & $\begin{array}{c}\text { Data } \\
\text { collection } \\
\text { methods }(\mathrm{E})\end{array}$ & $\begin{array}{c}\text { Withdrawal } \\
\& \text { dropouts }(\mathrm{F})\end{array}$ \\
\hline Boyd-Ball (2003) & Moderate & Moderate & Weak & N.A. & Weak & Strong \\
\hline Copello et al. (2009) & Moderate & Strong & Strong & Strong & Strong & Strong \\
\hline de los Angeles Cruz-Almanza et al. (2006) & Weak & Weak & Weak & Weak & Strong & Weak \\
\hline Doyle et al. (2003) & Weak & Weak & N.A. & Weak & Strong & Weak \\
\hline Dutcher et al. (2009) & Strong & Weak & N.A. & Weak & Strong & Weak \\
\hline Esposito-Smythers et al. (2006) & Weak & Weak & Weak & N.A. & Weak & Strong \\
\hline Fals-Stewart et al. (2005) & Weak & Strong & Weak & Weak & Strong & Weak \\
\hline Hansson et al. (2004) & Moderate & Strong & Weak & Strong & Strong & Strong \\
\hline Hansson et al. (2006) & Moderate & Strong & Weak & Strong & Strong & Strong \\
\hline Howells and Orford (2006) & Moderate & Weak & Weak & Weak & Strong & Weak \\
\hline Landau et al. (2004) & Weak & Weak & N.A. & Weak & Weak & Weak \\
\hline Latimer et al. (2003) & Moderate & Strong & Moderate & Weak & Strong & Strong \\
\hline Liddle et al. (2009) & Strong & Strong & Weak & Weak & Strong & Weak \\
\hline Nattala et al. (2010) & Weak & Strong & Weak & Weak & Strong & Strong \\
\hline O'Farrell et al. (2008) & Moderate & Strong & Moderate & N.A. & Strong & Strong \\
\hline Rychtarik and McGillicuddy (2005) & Weak & Strong & Moderate & Strong & Strong & Moderate \\
\hline Slesnick and Prestopnik (2009) & Moderate & Strong & Weak & N.A. & Strong & Weak \\
\hline Vedel et al. (2008) & Weak & Strong & Strong & Strong & Strong & Moderate \\
\hline Walitzer and Dermen (2004) & Weak & Strong & Weak & Weak & Strong & Moderate \\
\hline
\end{tabular}

Notes: Measured by the Dictionary for the Effective Public Health Practice Project Quality Assessment tool for Quantitative Studies (see Jackson, 2007). Information on Analysis $(\mathrm{G})$ and Intervention Integrity $(\mathrm{H})$ is contained in the text of the article. N.A. = not applicable.

2003; Liddle et al., 2009; Nattala et al., 2010; Rychtarik and McGillicuddy, 2005; Slesnick and Prestopnik, 2009; Vedel et al., 2008; Walitzer and Dermen, 2004). Eleven studies were conducted in the United States (Boyd-Ball, 2003; Dutcher et al., 2009; Esposito-Smythers et al., 2006; Fals-Stewart et al., 2005; Landau et al., 2004; Latimer et al., 2003; Liddle et al., 2009; O'Farrell et al., 2008; Rychtarik and McGillicuddy, 2005; Slesnick and Prestopnik, 2009; Walitzer and Dermen, 2004), three in the United Kingdom (Copello et al., 2009; Doyle et al., 2003; Howells and Orford, 2006), one in Mexico (de los Angeles Cruz-Almanza et al., 2006), three in Europe (Sweden and Holland) (Hansson et al., 2004, 2006; Vedel et al., 2008), and one in India (Nattala et al., 2010).

\section{Methodological adequacy}

Table 2 summarizes the methodological adequacy of the 19 studies. Two studies minimized selection bias by identifying a representative sample and obtaining a high consent rate (Dutcher et al., 2009; Liddle et al., 2009). Sixty-three percent of studies used a randomized control/clinical trial, thereby reducing the risk of allocation bias (Copello et al., 2009; Fals-Stewart et al., 2005; Hansson et al., 2004, 2006; Latimer et al., 2003; Liddle et al., 2009; Nattala et al., 2010; O'Farrell et al., 2008; Rychtarik and McGillicuddy, 2005; Slesnick and Prestopnik, 2009; Vedel et al., 2008; Walitzer and Dermen, 2004). Three quarters of the studies that reported differences between groups did not control for these baseline variations, making it difficult to ascertain whether posttest differences were attributed to the intervention (Esposito-Smythers et al., 2006; Fals-Stewart et al., 2005;
Hansson et al., 2004, 2006; Nattala et al., 2010; Slesnick and Prestopnik, 2009).

Twelve studies allocated participants evenly across groups (de los Angeles Cruz-Almanza et al., 2006; Fals-Stewart et al., 2005; Hansson et al., 2004, 2006; Latimer et al., 2003; Liddle et al., 2009; Nattala et al., 2010; O'Farrell et al., 2008; Rychtarik and McGillicuddy, 2005; Slesnick and Prestopnik, 2009; Vedel et al., 2008; Walitzer and Dermen, 2004). Outcome assessors were blinded in one third of the applicable studies (Copello et al., 2009; Hansson et al., 2004, 2006; Rychtarik and McGillicuddy, 2005; Vedel et al., 2008). Measures with established psychometric properties were used by $84 \%$ of studies (Copello et al., 2009; de los Angeles Cruz-Almanza et al., 2006; Doyle et al., 2003; Dutcher et al., 2009; Fals-Stewart et al., 2005; Hansson et al., 2004, 2006; Howells and Orford, 2006; Latimer et al., 2003; Liddle et al., 2009; Nattala et al., 2010; O'Farrell et al., 2008; Rychtarik and McGillicuddy, 2005; Slesnick and Prestopnik, 2009; Vedel et al., 2008; Walitzer and Dermen, 2004). Eight studies reported follow-up rates between $80 \%$ and $100 \%$ (Boyd-Ball, 2003; Copello et al., 2009; Esposito-Smythers et al., 2006; Hansson et al., 2004, 2006; Latimer et al., 2003; Nattala et al., 2010; O'Farrell et al., 2008).

Three studies justified the appropriateness of their analyses by referencing a source for their statistical approach (Copello et al., 2009; de los Angeles Cruz-Almanza et al., 2006; Liddle et al., 2009). Follow-up rates varied from $9 \%$ (Vedel et al., 2008) to 98\% (Latimer et al., 2003; O'Farrell et al., 2008; Slesnick and Prestopnik, 2009), and intent-to-treat analyses were reported by one third of studies (Copello et al., 2009; Latimer et al., 2003; Liddle et al., 2009; O'Farrell 
et al., 2008; Rychtarik and McGillicuddy, 2005; Slesnick and Prestopnik, 2009; Walitzer and Dermen, 2004).

Methods to optimize intervention fidelity were not reported by two studies (Boyd-Ball, 2003; Hansson et al., 2004). When reported, most commonly reported methods to optimize intervention fidelity were therapist training (Copello et al., 2009; de los Angeles Cruz-Almanza et al., 2006; Doyle et al., 2003; Dutcher et al., 2009; Hansson et al., 2006; Howells and Orford, 2006; Landau et al., 2004; Latimer et al., 2003; Nattala et al., 2010; Rychtarik and McGillicuddy, 2005; Slesnick and Prestopnik, 2009; Vedel et al., 2008; Walitzer and Dermen, 2004), therapist supervision (Copello et al., 2009; Howells and Orford, 2006; Landau et al., 2004; Latimer et al., 2003; Nattala et al., 2010; O'Farrell et al., 2008; Rychtarik and McGillicuddy, 2005; Slesnick and Prestopnik, 2009; Vedel et al., 2008; Walitzer and Dermen, 2004), and intervention manuals/protocol (Copello et al., 2009; Esposito-Smythers et al., 2006; Fals-Stewart et al., 2005; Hansson et al., 2006; Landau et al., 2004; O’Farrell et al., 2008; Rychtarik and McGillicuddy, 2005; Vedel et al., 2008; Walitzer and Dermen, 2004). Of the 14 studies with more than one group, participants were evenly recruited into groups for 12 studies (de los Angeles Cruz-Almanza et al., 2006; Fals-Stewart et al., 2005; Hansson et al., 2004, 2006; Latimer et al., 2003; Liddle et al., 2009; Nattala et al., 2010; O'Farrell et al., 2008; Rychtarik and McGillicuddy, 2005; Slesnick and Prestopnik, 2009; Vedel et al., 2008; Walitzer and Dermen, 2004). Contamination was likely for six studies (de los Angeles Cruz-Almanza et al., 2006; EspositoSmythers et al., 2006; Howells and Orford, 2006; Rychtarik and McGillicuddy, 2005; Vedel et al., 2008; Walitzer and Dermen, 2004).

\section{Effects}

A meta-analysis using the most commonly reported outcomes (which were alcohol use among problem drinkers and coping among their family members) was explored but judged inappropriate, given the variability between studies in the outcomes reported. The most commonly reported effect for problem drinkers was decreased alcohol consumption (Boyd-Ball, 2003; Doyle et al., 2003; Esposito-Smythers et al., 2006; Fals-Stewart et al., 2005; Latimer et al., 2003; Liddle et al., 2009; Nattala et al., 2010; O'Farrell et al., 2008; Slesnick and Prestopnik, 2009; Walitzer and Dermen, 2004). The most commonly reported effect for family members of problem drinkers was improved coping (de los Angeles Cruz-Almanza et al., 2006; Hansson et al., 2004; Howells and Orford, 2006). Of the eight studies measuring family functioning, four reported improvements in family functioning (Liddle et al., 2009; Nattala et al., 2010; Slesnick and Prestopnik, 2009; Vedel et al., 2008). In addition to measures of effect, three studies measured level of participant engagement in treatment to be 55\% (Dutcher et al., 2009), 83\%
(Landau et al., 2004), and 92\% (O'Farrell et al., 2008). Two interventions investigated the cost of the evaluated interventions: one based solely on the length of sessions (Vedel et al., 2008) and the other calculated cost-effectiveness ratios for participants using the change in percentage of heavy drinking days from baseline to follow-up (Fals-Stewart et al., 2005).

\section{Discussion}

Although an encouraging 18 of the 19 family-based interventions yielded a positive effect, methodological deficiencies in evaluation designs across all studies resulted in less-than-optimal evidence.

\section{Methodological adequacy}

The rating of studies across methodological review criteria was variable. For example, although $84 \%$ of studies were rated as strong for data collection methods, selection bias was rated as weak for $47 \%$ of studies. Most studies did not control for confounders, even when identified. Followup rates varied from $9 \%$ to $98 \%$, and one third of studies performed an intent-to-treat analysis. Methodological quality was similar for reviewed interventions targeting problem drinkers and their family members, compared with interventions for family members of problem drinkers only, although allocation bias was rated more strongly for the former and blinding was rated more strongly for the latter. Variable reporting of an intervention evaluation makes it difficult for the intervention to be replicated or adapted for other populations and settings or for wider implementation.

\section{Limitations of the available literature}

Large variation in eligibility criteria for different studies limits their comparability. Measurement of the primary criteria of an alcohol use disorder or problem was diverse for studies that targeted problem drinkers and their family members. Comparability between studies would be improved by using a standard measure of alcohol misuse, such as the AUDIT (Saunders et al., 1993) or the Diagnostic and Statistical Manual of Mental Disorders, Fourth Edition (DSM-IV), criteria (American Psychiatric Association, 1994).

All studies $(n=19)$ used self-report measures. Non-self-report measures were also used by six studies. Reliance on self-report to measure health outcomes is problematic because the method is prone to biases, even when bias is minimized by using psychometrically validated tools (Hogan, 2003). A combination of objective non-self-report and self-report measures would increase confidence in the validity of outcome findings. For example, information from medical records has been shown to be both suitable and efficient for evaluating interventions 
targeting a range of health and social outcomes (Landau et al., 2004; O'Farrell et al., 2008; Samet et al., 2003), particularly if common challenges to its collection and use, such as limitations in data access and poor data quality (Safran, 1991), can be overcome.

Intervention costs were measured by two studies, but neither completed a full economic evaluation. An economic component is increasingly recognized as integral to any evaluation because it provides relevant information on the potential efficiency of allocating health care resources (Drummond and McGuire, 2001). Essential to any economic evaluation is a rigorous assessment of both intervention costs and consequences compared with current practice. Comparability of results between economic evaluation studies is further made possible by the adoption of a commonly used validated health outcome measure such as the quality-adjusted life year or disability-adjusted life year.

\section{Interventions with potential to be tailored to indigenous communities}

This review identified only one intervention study targeting an indigenous population (Native Americans; Boyd-Ball, 2003), a study that was not methodologically strong. The lack of evaluations of family-based interventions targeting indigenous people is somewhat surprising given that indigenous family members are typically present at health services and participate in communication about familial health problems with health practitioners (King and Turia, 2002; McCubbin, 2006; McGrath et al., 2006). Therefore, their involvement in programs to reduce alcohol-related harm fits with usual care practices. This review identified family and cognitive-behavioral therapy (Latimer et al., 2003) and multidimensional family therapy (Liddle et al., 2009) as effective and robustly evaluated problem-drinker-targeted interventions that include a family member. Family members of problem drinkers experience negative consequences of their relative's drinking (Kelly and Kowalyszyn, 2003; Laslett et al., 2010; Seale et al., 2002), and therefore programs targeting family members in their own right that also address problem drinker outcomes are likely to be acceptable and appropriate for delivery in indigenous communities to reduce alcohol-related harms. Effective programs identified by this review, targeting family members and focusing on outcomes of the problem drinker and those of their family member, are Community Reinforcement and Family Training (Dutcher et al., 2009), coping skills training, and 12-step facilitation (Rychtarik and McGillicuddy, 2005).

To ensure that these best evidence family-based approaches are appropriate and acceptable for delivery to indigenous people, they should be adapted for integration into indigenous-specific health care in collaboration with locally targeted indigenous communities.

\section{Potential limitations of the review}

Although a rigorous and thorough search strategy was used, there is a possibility that the review did not locate all relevant studies. Relevant intervention evaluations may have been misclassified; however, a sufficient agreement between blinded coders $(\kappa=.58)$ suggests otherwise. Last, because evaluations with statistically significant findings are more likely to be published, it is possible that the published evaluations reviewed overestimate the interventions' true effectiveness (Dickersin et al., 1987; Easterbrook et al., 1991).

\section{Conclusions}

Although family-based approaches appear effective in engaging problem drinkers into treatment and reducing their risk of alcohol-related harms, the evidence base for their cost-effectiveness would be strengthened by evaluation studies that recruit more representative samples, include confounding variables in analyses, improve consent and follow-up rates, and conduct high-quality economic evaluations. Given the central role that family relationships play in reinforcing behavior and maintaining social cohesion in indigenous communities, family-based approaches offer considerable promise for reducing alcohol-related harms among indigenous peoples. Family-based interventions are more likely to be acceptable, appropriate, and effective for indigenous peoples if (a) adapted with the input of indigenous community members (Masotti et al., 2006); (b) the involvement of family members who are themselves problem drinkers is not automatically excluded, because their exclusion is not practical in the context of routine delivery of health care services due to clustering of alcohol problems within racial minority family groups (Seale et al., 2010); (c) therapists delivering the intervention are trained and supervised to optimize intervention fidelity (Miller et al., 2006); and (d) the intervention is manualized for integration into health service protocols and procedures but has sufficient flexibility to meet the needs of individual clients (Liddle, 2004).

\section{References}

Allison, M., Rivers, P. A., \& Fottler, M. D. (2004). Can community health center funding enhance health services for Native American tribes and organizations? Journal of Health Care for the Poor and Underserved, 15, 193-205.

American Psychiatric Association. (1994). Diagnostic and statistical manual of mental disorders (4th ed.). Washington, DC: Author.

Australian Department of Human Services and Health. (1995). National Drug Strategy household survey: Urban Aboriginal and Torres Strait Islander peoples supplement 1994. Canberra, Australia: Australian Government. Retrieved from http://catalogue.nla.gov.au/Record/1026165.

Begg, S., Vos, T., Barker, B., Stevenson, C., Stanley, L., \& Lopez, A. D. (2007). The burden of disease and injury in Australia 2003 (AIHW cat. no. PHE 82). Canberra, Australia: Australian Institute of Health and 
Welfare. Retrieved from http://www.aihw.gov.au/publications/index. $\mathrm{cfm} / \mathrm{title} / 10317$

Bernal, G. B., Jiménez-Chafey, M. I., \& Domenech Rodríguez, M. M. (2009). Cultural adaptation of treatments: A resource for considering culture in evidence-based practice. Professional Psychology: Research and Practice, 40, 361-368.

Berry, S. L., \& Crowe, T. P. (2009). A review of engagement of Indigenous Australians within mental health and substance abuse services. $A d$ vances in Mental Health, 8, 16-27.

Boyd-Ball, A. J. (2003). A culturally responsive, family-enhanced intervention model. Alcoholism: Clinical and Experimental Research, 27, 1356-1360.

Bramley, D., Broad, J., Harris, R., Reid, P., \& Jackson, R., for the Alcohol Burden of Disease and Disability Group. (2003, October 24). Differences in patterns of alcohol consumption between Maori and non-Maori in Aotearoa (New Zealand). New Zealand Medical Journal, 116(1184), U645.

Calabria, B., Doran, C. M., Vos, T., Shakeshaft, A. P., \& Hall, W. (2010). Epidemiology of alcohol-related burden of disease among Indigenous Australians. Australian and New Zealand Journal of Public Health, 34, Supplement 1, S47-S51.

Calabria, B., Shakeshaft, A. P., \& Havard, A. (2011). A systematic and methodological review of interventions for young people experiencing alcohol-related harm. Addiction, 106, 1406-1418.

Centers for Disease Control and Prevention. (2008). Alcohol-attributable deaths and years of potential life lost among American Indians and Alaska Natives, United States, 2001-2005. MMWR 57(34), 938-941. Retrieved from http://www.cdc.gov/mmwr/preview/mmwrhtml/ mm5734a3.htm

Coates, K. S. (2004). A global history of indigenous peoples: Struggle and survival. New York, NY: Palgrave MacMillan.

Connor, J., Broad, J., Jackson, R., Vander Hoorn, S., \& Rehm, J. (2004). The burden of death, disease and disability due to alcohol in New Zealand: Research summary. Auckland, New Zealand: University of Auckland. Retrieved from http://www.alac.org.nz/sites/default/files/researchpublications/pdfs/BurdenExec.pdf

Copello, A., Templeton, L., Orford, J., Velleman, R., Patel, A., Moore, L., ... Godfrey, C. (2009). The relative efficacy of two levels of a primary care intervention for family members affected by the addiction problem of a close relative: A randomized trial. Addiction, 104, 49-58.

Copello, A. G., Velleman, R. D. B., \& Templeton, L. J. (2005). Family interventions in the treatment of alcohol and drug problems. Drug and Alcohol Review, 24, 369-385.

de los Angeles Cruz-Almanza, M., Gaona-Márquez, L., \& Sánchez-Sosa, J. J. (2006). Empowering women abused by their problem drinker spouses: Effects of a cognitive-behavioral intervention. Salud Mental, 29, 25-31. Retrieved from http://redalyc.uaemex.mx/pdf/582/58229504.pdf

Dickersin, K., Chan, S., Chalmers, T. C., Sacks, H. S., \& Smith, H., Jr. (1987). Publication bias and clinical trials. Controlled Clinical Trials, 8, 343-353.

Dodgson, J. E., \& Struthers, R. (2005). Indigenous women's voices: Marginalization and health. Journal of Transcultural Nursing, 16, 339-346.

Doyle, M., Carr, A., Rowen, S., Galvin, P., Lyons, S., \& Cooney, G. (2003). Family-oriented treatment for people with alcohol problems in Ireland: A comparison of the effectiveness of residential and community-based programmes. Journal of Family Therapy, 25, 15-40.

Drummond, M., \& McGuire, A. (2001). Economic evaluation in health care. Oxford, England: Oxford University Press.

Dutcher, L. W., Anderson, R., Moore, M., Luna-Anderson, C., Meyers, R. J., Delaney, H. D., \& Smith, J. E. (2009). Community Reinforcement and Family Training (CRAFT): An effectiveness study. Journal of Behavior Analysis in Health, Sports, Fitness and Medicine, 2, 82-93.

Easterbrook, P. J., Gopalan, R., Berlin, J. A., \& Matthews, D. R. (1991). Publication bias in clinical research. The Lancet, 337, 867-872.
Esposito-Smythers, C., Spirito, A., Uth, R., \& LaChance, H. (2006). Cognitive behavioral treatment for suicidal alcohol abusing adolescents: Development and pilot testing. The American Journal on Addictions, 15, Supplement s1, s126-s130.

Fals-Stewart, W., Klostermann, K., Yates, B. T., O’Farrell, T. J., \& Birchler, G. R. (2005). Brief relationship therapy for alcoholism: A randomized clinical trial examining clinical efficacy and cost-effectiveness. Psychology of Addictive Behaviors, 19, 363-371.

First Nations/First Nationals Information Governance Committee. (2007). First Nations Regional Longitudinal Health Survey (RHS) 2002/03: Results for adults, youth and children living in First Nation communities. Ottawa, Canada: Assembly of First Nations/First Nations Information Governance Committee. Retrieved from http://rhs-ers.ca/sites/default/ files/ENpdf/RHS_2002/rhs2002-03-technical_report.pdf.

Gray, D., Stearne, A., Wilson, M., \& Doyle, M. (2010). Indigenous-specific alcohol and other drug interventions: Continuities, changes and areas of greatest need (ANCD research paper 20). Canberra, Australia: National Indigenous Drug and Alcohol Committee and Australian National Council on Drugs. Retrieved from http://www.ilc.unsw.edu.au/sites/ilc. unsw.edu.au/files/mdocs/Report $\% 20$ NIDAC_ANCD $\% 20$ research $\% 20$ paper_Apr10.pdf.

Hansson, H., Rundberg, J., Zetterlind, U., Johnsson, K. O., \& Berglund, M. (2006). An intervention program for university students who have parents with alcohol problems: A randomized controlled trial. Alcohol and Alcoholism, 41, 655-663.

Hansson, H., Zetterlind, U., Aberg-Orbeck, K., \& Berglund, M. (2004). Twoyear outcome of coping skills training, group support and information for spouses of alcoholics: A randomized controlled trial. Alcohol and Alcoholism, 39, 135-140.

Havard, A., Shakeshaft, A., \& Sanson-Fisher, R. (2008). Systematic review and meta-analyses of strategies targeting alcohol problems in emergency departments: Interventions reduce alcohol-related injuries. Addiction, 103, 368-376.

Hayman, N. E., White, N. E., \& Spurling, G. K. (2009). Improving Indigenous patients' access to mainstream health services: The Inala experience. Medical Journal of Australia, 190, 604-606.

Hogan, T. P. (2003). Psychological testing: A practical introduction. New York, NY: John Wiley \& Sons.

Howells, E., \& Orford, J. (2006). Coping with a problem drinker: A therapeutic intervention for the partners of problem drinkers, in their own right. Journal of Substance Use, 11, 53-71.

Jackson, N. (2007). Handbook: Systematic reviews of health promotion and public health interventions. Retrieved from the Cochrane Collaboration at http://ph.cochrane.org/sites/ph.cochrane.org/files/uploads/HPPH_systematic_review_handbook.pdf

Kelly, A. B., \& Kowalyszyn, M. (2003). The association of alcohol and family problems in a remote indigenous Australian community. Addictive Behaviors, 28, 761-767.

King, A., \& Turia, T. (2002). He Korowai Oranga: Māori Health Strategy. Wellington, New Zealand: Ministry of Health. Retrieved from http://www. health.govt.nz/publication/he- korowai-oranga-maori-health-strategy.

KnowledgeAssets. (2010). Racial and ethnic disparities in substance abuse treatment. (Version 3). Knol Retrieved from http://knol.google.com $/ \mathrm{k} /$ saprp-knowledgeassets/racial-and-ethnic-disparities-in/13kykpwd3qs47/15

Landau, J., Stanton, M. D., Brinkman-Sull, D., Ikle, D., McCormick, D., Garrett, J., . . W Wamboldt, F. (2004). Outcomes with the ARISE approach to engaging reluctant drug- and alcohol-dependent individuals in treatment. American Journal of Drug and Alcohol Abuse, 30, 711-748.

Laslett, A.-M., Catalano, P., Chikritzhs, T., Dale, C., Doran, C., Ferris, J., ... Wilkinson, C. (2010). The range and magnitude of alcohol's harm to others. Canberra, Australia: AER Centre for Alcohol Policy Research, Turning Point Alcohol and Drug Centre, Eastern Health. Retrieved from http://www.fare.org.au/wp-content/uploads/2011/07/The-Range- 
and-Magnitude-of-Alcohol\%E2\%80\%99s-Harm-to-Others-report. pdf?9d7bd4.

Latimer, W. W., Winters, K. C., D’Zurilla, T., \& Nichols, M. (2003). Integrated family and cognitive-behavioral therapy for adolescent substance abusers: A stage I efficacy study. Drug and Alcohol Dependence, 71, 303-317.

Lau, A. S. (2006). Making the case for selective and directed cultural adaptations of evidence-based treatments: Examples from parent training. Clinical Psychology: Science and Practice, 13, 295-310.

Liddle, H. A. (2004). Family-based therapies for adolescent alcohol and drug use: Research contributions and future research needs. Addiction, 99, Supplement s2, 76-92.

Liddle, H. A., Rowe, C. L., Dakof, G. A., Henderson, C. E., \& Greenbaum, P. E. (2009). Multidimensional family therapy for young adolescent substance abuse: Twelve-month outcomes of a randomized controlled trial. Journal of Consulting and Clinical Psychology, 77, 12-25.

Masotti, P., George, M. A., Szala-Meneok, K., Morton, A. M., Loock, C., Van Bibber, M., . . . MacLeod, S. (2006). Preventing fetal alcohol spectrum disorder in Aboriginal communities: A methods development project. PLoS Medicine, 3, 24-29. Retrieved from http://www.plosmedicine.org/article/info:doi/10.1371/journal.pmed.0030008

McCubbin, L. D. (2006). Indigenous values, cultural safety and improving health care: The case of Native Hawaiians. Contemporary Nurse, 22, 214-217.

McGrath, P., Patton, M. A., Holewa, H., \& Rayne, R. (2006). The importance of the 'family meeting' in health care communication with Indigenous people: Findings from an Australian study. Australian Journal of Primary Health, 12, 56-64.

McLennan, V., \& Khavarpour, F. (2004). Culturally appropriate health promotion: Its meaning and application in Aboriginal communities. Health Promotion Journal of Australia, 15, 237-239.

Miller, W. R., Sorensen, J. L., Selzer, J. A., \& Brigham, G. S. (2006). Disseminating evidence-based practices in substance abuse treatment: A review with suggestions. Journal of Substance Abuse Treatment, 31, 25-39.

Miller, W. R., \& Wilbourne, P. L. (2002). Mesa Grande: A methodological analysis of clinical trials of treatments for alcohol use disorders. Addiction, 97, 265-277.

Nagel, T., \& Thompson, C. (2010). The central role of Aboriginal families in motivational counselling: Family support and family 'humbug'. Australian Indigenous HealthBulletin, 10, 1-12. Retrieved from http:// healthbulletin.org.au/wp-content/uploads/2010/01/bulletin_original_articles_nagel.pdf

National Drug Research Institute. Indigenous Australian alcohol and other drugs bibliographic database. Retrieved from http://www.db.ndri.curtin. edu.au

Nattala, P., Leung, K. S., Nagarajaiah, \& Murthy, P. (2010). Family member involvement in relapse prevention improves alcohol dependence outcomes: A prospective study at an addiction treatment facility in India. Journal of Studies on Alcohol and Drugs, 71, 581-587.

O'Farrell, T. J., Murphy, M., Alter, J., \& Fals-Stewart, W. (2008). Brief family treatment intervention to promote continuing care among alcoholdependent patients in inpatient detoxification: A randomized pilot study. Journal of Substance Abuse Treatment, 34, 363-369.

Rychtarik, R. G., \& McGillicuddy, N. B. (2005). Coping skills training and 12-step facilitation for women whose partner has alcoholism: Effects on depression, the partner's drinking, and partner physical violence. Journal of Consulting and Clinical Psychology, 73, 249-261.
Safran, C. (1991). Using routinely collected data for clinical research. Statistics in Medicine, 10, 559-564.

Samet, J. H., Larson, M. J., Horton, N. J., Doyle, K., Winter, M., \& Saitz, R. (2003). Linking alcohol- and drug-dependent adults to primary medical care: A randomized controlled trial of a multi-disciplinary health intervention in a detoxification unit. Addiction, 98, 509-516.

Saunders, J. B., Aasland, O. G., Babor, T. F., de la Fuente, J. R., \& Grant, M. (1993). Development of the Alcohol Use Disorders Identification Test (AUDIT): WHO collaborative project on early detection of persons with harmful alcohol consumption-II. Addiction, 88, 791-804.

Seale, J. P., Shellenberger, S., Rodriguez, C., Seale, J. D., \& Alvarado, M. (2002). Alcohol use and cultural change in an Indigenous population: A case study from Venezuela. Alcohol and Alcoholism, 37, 603-608.

Seale, J. P., Shellenberger, S., Sanchez, N., Vogel, R. L., Villalobos, E., Girton, F. S., . . Okosun, I. S. (2010). Characteristics of problem drinking in an urban South American Indigenous population. Substance Use \& Misuse, 45, 2185-2202.

Seale, J. P., Shellenberger, S., \& Spence, J. (2006). Alcohol problems in Alaska Natives: Lessons from the Inuit. American Indian and Alaska Native Mental Health Research, 13, 1-31.

Shakeshaft, A. P., Bowman, J. A., \& Sanson-Fisher, R. W. (1997). Behavioural alcohol research: New directions or more of the same? Addiction, 92, 1411-1422.

Slesnick, N., \& Prestopnik, J. L. (2009). Comparison of family therapy outcome with alcohol-abusing, runaway adolescents. Journal of Marital \& Family Therapy, 35, 255-277.

Smit, E., Verdurmen, J., Monshouwer, K., \& Smit, F. (2008). Family interventions and their effect on adolescent alcohol use in general populations; a meta-analysis of randomized controlled trials. Drug and Alcohol Dependence, 97, 195-206.

Subramanian, S. V., Smith, G. D., \& Subramanyam, M. (2006). Indigenous health and socioeconomic status in India. PLoS Medicine, 3, 1794-1804. Retrieved from http://www.plosmedicine.org/article/info:doi/10.1371/ journal.pmed.0030421.

Templeton, L., Velleman, R., \& Russell, C. (2010). Psychological interventions with families of alcohol misusers: A systematic review. Addiction Research \& Theory, 18, 616-648.

Vedel, E., Emmelkamp, P. M. G., \& Schippers, G. M. (2008). Individual cognitive-behavioral therapy and behavioral couples therapy in alcohol use disorder: A comparative evaluation in community-based addiction treatment centers. Psychotherapy and Psychosomatics, 77, 280-288.

Vos, T., Barker, B., Stanley, L., \& Lopez, A. (2003). The burden of disease and injury in Aboriginal and Torres Strait Islander peoples 2003. Brisbane, Australia: School of Population Health, University of Queensland. Retrieved from http://www.lowitja.org.au/files/crcah_docs/IndigenousBoD-Report.pdf

Walitzer, K. S., \& Dermen, K. H. (2004). Alcohol-focused spouse involvement and behavioral couples therapy: Evaluation of enhancements to drinking reduction treatment for male problem drinkers. Journal of Consulting and Clinical Psychology, 72, 944-955.

Webb, G., Shakeshaft, A., Sanson-Fisher, R., \& Havard, A. (2009). A systematic review of work-place interventions for alcohol-related problems. Addiction, 104, 365-377.

Wood, E., Shakeshaft, A., Gilmour, S., \& Sanson-Fisher, R. (2006). A systematic review of school-based studies involving alcohol and the community. Australian and New Zealand Journal of Public Health, $30,541-549$. 